\title{
O turismo religioso realizado na Pedra de Santo Antônio em Fagundes-PB: reflexões sobre os impactos socioambientais
}

\author{
Reliious tourism at Pedra de Santo Antônio in Fagundes-PB: reflections on social and \\ environmental impacts
}

Turismo religioso en la Pedra de Santo Antônio en Fagundes-PB: reflexiones sobre impactos sociales y ambientales

Igo Marinho Serafim Borges ORCID: https://orcid.org/0000-0002-3662-1859 Universidade Federal de Campina Grande, Brasil E-mail: igomarinho27@gmail.com Amanda Cristiane Gonçalves Fernandes ORCID: https://orcid.org/0000-0001-8462-6171 Universidade Federal de Campina Grande, Brasil E-mail: amandafernandestt@gmail.com Jean Oliveira Campos ORCID: https://orcid.org/0000-0002-2874-754X Universidade Estadual da Paraíba, Brasil E-mail: jeannolliveira@gmail.com Jéssica Araújo Silva ORCID: https://orcid.org/0000-0002-2996-2137 Universidade Federal de Campina Grande E-mail: jeharaujo03@gmail.com

Anderson Felipe Leite dos Santos ORCID: https://orcid.org/0000-0002-1947-5175

Faculdade de Ciências e Tecnologia, Brasil E-mail: anderson.felipe@unesp.br

Emanuelly Cristovão Barbosa da Silva ORCID: https://orcid.org/0000-0003-3835-1132

Universidade Estadual da Paraíba, Brasil E-mail: cristovamemanuelly@gmail.com

Raphael da Silva Eduardo ORCID: https://orcid.org/0000-0002-5968-7578 Universidade Federal de Campina Grande, Brasil E-mail: raphael_leahpar17@hotmail.com

Cleibson Lima Silva

ORCID: https://orcid.org/0000-0002-0663-8828 Centro Universitário Maurício de Nassau, Brasil E-mail: cleibson.cls@gmail.com

Joaquim Rangel Andrade da Silva ORCID: https://orcid.org/0000-0002-8183-1126 Universidade Estadual da Paraíba, Brasil E-mail: rangelandrade83@gmail.com Ramon Marinho Gomes ORCID: https://orcid.org/0000-0001-8382-8628 Universidade Estadual da Paraíba, Brasil E-mail: ramongomes032@gmail.com Cecília Elisa de Sousa Muniz ORCID: https://orcid.org/0000-0002-7402-9354 Universidade Federal de Campina Grande, Brasil E-mail: ceciliamuniz.qi@gmail.com

Paulo de Souza Albuquerque Junior ORCID: https://orcid.org/0000-0003-0704-7998 Universidade Estadual da Paraíba, Brasil E-mail: paulojuniorh13@gmail.com

\section{Resumo}

O presente artigo discute a importância do turismo religioso como um dos principais segmentos que vem sendo desenvolvido de forma contínua desde o início do desenvolvimento das práticas turísticas. Dessa forma, este artigo tem 
como objetivo destacar e analisar a prática do turismo religioso na Pedra de Santo Antônio e ressaltar o a movimentação econômica que essa atividade pode fornecer para o município de Fagundes-PB, além de evidenciar os problemas ambientais decorrentes da atividade turística. A metodologia aplicada no estudo compreende um estudo de caso e uma revisão de literatura, abordando aspectos turísticos da cidade de Fagundes com ênfase no desenvolvimento econômico do município. Os resultados obtidos com a pesquisa ressaltam o grande potencial turístico do município quando relacionado ao turismo religioso, no entanto ainda há falta de investimentos governamentais para que o turismo local se desenvolva, gerando mais empregos para a população local. Outro ponto que chama atenção é o despreparo estrutural do município para receber os turistas, visto que a cidade não oferece estadas para os turistas e os visitantes que procuram a Pedra de Santo Antônio. Conclui-se que, para a cidade se desenvolver como meio turístico, são necessários investimentos na estrutura, além de se tornar mais aconchegante, visto que muitas pessoas quando não são bem acolhidas (instalados) não voltam mais ao ponto turístico e nem indica as pessoas próximas.

Palavras-chave: Economia; Infraestrutura; Investimentos governamentais.

\begin{abstract}
This article discusses the importance of religious tourism as one of the main segments that has been continuously developed since the beginning of the development of tourism practices. Thus, this article aims to highlight and analyze the practice of religious tourism in Pedra de Santo Antônio and highlight the economic movement that this activity can provide for the municipality of Fagundes-PB, in addition to highlighting the environmental problems arising from tourism. The methodology applied in the study comprises a case study and a literature review, addressing tourist aspects of the city of Fagundes with an emphasis on the economic development of the city. The results obtained from the research highlight the great tourist potential of the city when related to religious tourism, however there is still a lack of government investments for local tourism to develop, generating more jobs for the local population. Another point that draws attention is the municipality's structural unpreparedness to receive tourists, as the city does not offer accommodation for tourists and visitors looking for Pedra de Santo Antônio. It is concluded that, for the city to develop as a touristic environment, investments in the structure are necessary, in addition to becoming more cozy, since many people when they are not welcomed (installed) do not return to the tourist spot or refer people nearby.
\end{abstract}

Keywords: Economy; Infrastructure; Government investments.

\title{
Resumen
}

En este artículo se analiza la importancia del turismo religioso como uno de los principales segmentos que se ha venido desarrollando continuamente desde el inicio del desarrollo de las prácticas turísticas. Así, este artículo tiene como objetivo resaltar y analizar la práctica del turismo religioso en Pedra de Santo Antônio y resaltar el movimiento económico que esta actividad puede brindar al municipio de Fagundes-PB, además de resaltar los problemas ambientales derivados del turismo. La metodología aplicada en el estudio comprende un estudio de caso y una revisión de la literatura, abordando aspectos turísticos de la ciudad de Fagundes con énfasis en el desarrollo económico de la ciudad. Los resultados obtenidos con la investigación destacan el gran potencial turístico de la ciudad cuando se relaciona con el turismo religioso, sin embargo aún existe una falta de inversiones gubernamentales para que el turismo local se desarrolle, generando más empleos para la población local. Otro punto que llama la atención es la falta de preparación estructural del municipio para recibir turistas, ya que la ciudad no ofrece alojamiento para turistas y visitantes que buscan Pedra de Santo Antônio. Se concluye que, para que la ciudad se desarrolle como un entorno turístico, son necesarias inversiones en la estructura, además de hacerse más acogedoras, ya que muchas personas cuando no son acogidas (instaladas) no regresan al punto turístico ni refieren personas cercanas.

Palabras clave: Economía; Infraestructura; Inversiones gubernamentales.

\section{Introdução}

De acordo com a definição apresentada pela Empresa Brasileira de Promoção Internacional do Turismo - EMBRATUR, o turismo é uma atividade econômica representada pelo conjunto de transações, compra e venda de serviços turísticos, efetuadas entre os agentes econômicos da atividade. É gerado pelo deslocamento voluntário e temporário de pessoas para fora dos limites da área ou região em que têm residência fixa, por qualquer motivo, excetuando-se o de exercer alguma atividade remunerada no local que visita (Rocha, 2005).

Na visão de Blos (2004), o turismo é um conjunto de relações e de fenômenos produzidos pelo deslocamento e pela permanência de pessoas fora do lugar de domicílio, desde que tais deslocamentos e permanência não estejam motivados por uma atividade lucrativa. Faz-se oportuno destacar que, conforme colocações de Guimarães (2020), esse conjunto de relações quando realizados sem planejamento algum pode afetar de forma direta o meio ambiente, causando perturbações aos recursos naturais dependendo da prática atualizada na atividade turística. 
O turismo é uma prática social e econômica que vem sendo bem desenvolvida nos últimos anos. Entre as suas ramificações, por exemplo: tem-se o turismo de negócios e eventos, o turismo religioso, o turismo cultural, o turismo de pesca, o turismo rural, o turismo de esporte, o turismo da saúde, entre outros diversos segmentos turísticos que geram, por conseguinte, empregos e renda para o país (Ruschmann, 2016). No entanto, quando a atividade turística não tem planejamento adequado, algumas condições preocupantes podem surgir e afetar de forma negativa o meio ambiente. $\mathrm{O}$ turismo é uma atividade muito importante para a economia do país, mas para que isso aconteça é necessário ter investimento na infraestrutura do local, a fim de desenvolver práticas turísticas de forma sustentável, ou seja, sem que cause grandes danos aos recursos naturais (Silva, 2013). Nesse sentido, pode-se pensar sempre em estratégias que reduzam esses impactos no ambiente.

Dentre os diversos segmentos ou nichos do mercado turístico, na atualidade, o turismo religioso tem se destacado de forma expressiva. Essa segmentação pode ser entendida como uma atividade desenvolvida por pessoas que se deslocam de um lugar para outro por motivos religiosos (Azevedo, 2015). Esse deslocamento gera lucro de diversas formas como hospedagem, passagens aéreas e terrestres, e consumo, questões alimentícias e cultural local, como réplicas do local turístico visitado (Correia, 2019).

Destaca-se como práticas turísticas mal planejadas, a atividade turística da Pedra de Santo Antônio, no município de Fagundes na Paraíba. É perceptível os problemas ambientais causados nas proximidades onde se localiza Pedra, a exemplo da poluição referente a resíduos deixados pelos turistas e das construções irregulares nas localidades que causam problemas ambientais em decorrência da derrubada da vegetação local para a construção de casa e de bares (Silva, 2012). Diante do exposto, o objetivo do presente trabalho foi destacar e analisar o turismo religioso na Pedra de Santo Antônio-PB e ressaltar o poder econômico que essa atividade pode fornecer para a economia do município de Fagundes-PB, levando em consideração os problemas ambientais causados pela atividade turística nas proximidades.

\section{Fundamentação Teórica}

\subsection{O turismo e sua importância como atividade econômica para o desenvolvimento local}

Turismo pode ser entendido como o ato de viajar, se deslocar a outros lugares independente da distância, para fins de entretenimento, educacionais, de diversão, entre outros. A necessidade de aprender e ter contato com outras culturas, visitar e conhecer lugares com paisagens naturais ou históricas ou apenas ficar um tempo descansando, longe da correria do dia a dia, caracteriza a atividade do turismo (Panosso \& Netto, 2010).

O turismo dentro de sua dinâmica apresenta-se como uma área de fundamental importância na sociedade atual, seja por sua importância econômica, sua relevância social e seu papel na preservação do meio ambiente e patrimônio cultural (Barreto, 2007). Toda sociedade possui características diferentes umas das outras, peculiaridades culturais e sociais, e o turismo engloba e depende dessas peculiaridades, através de serviços e produtos que são ofertados.

O desenvolvimento de um determinado local de interesse turístico está sujeito aos tipos de estratégias que são implantadas e às características de cada local. Algumas estratégias podem apresentar resultados positivos, enquanto outras podem ser desastrosas e dificilmente reversíveis (Nunes, 2009). Na maior parte, os empreendedores da atividade turística trabalham com esses aspectos simplesmente no setor econômico, deixando de considerar os riscos e benefícios que a atividade pode desencadear em outros setores.

Essa perspectiva baseada na economia elabora planos e estratégias para que a localidade produza produtos e serviços que possam ser consumidos pelos viajantes que, em troca do usufruto de tal produção, deixam no destino algum dinheiro, contribuindo assim para o desenvolvimento econômico do local (Scótolo; Netto, 2015). Segundo Dall'agnol, (2012) ainda que o turismo possa gerar impactos positivos significativos nas cidades e regiões receptoras, quando mal planejado e gerido, pode gerar externalidades negativas ao núcleo receptor e refletir seus impactos para além do destino visitado. 


\subsubsection{A atividade turística e o segmento religioso}

O turismo engloba vários segmentos de acordo com a atividade que será realizada ou com os objetivos da viagem, excursão, expedição, etc. O turismo religioso caracterizasse como uma atividade turística ligada a manifestações religiosas. Essa prática possui origens antigas que podem ser cristãs ou não cristãs. Na antiguidade a busca por templos e lugares sagrados ainda não era entendida como atividade econômica. Essa consolidação só foi dada a partir do início do século XX, quando começaram a promover o turismo religioso em busca de riquezas (Pereira et al., 2008).

No Brasil um dos pontos de visitação mais procurados é a "capital da fé", no Santuário Nacional de Nossa Senhora Aparecida, localizado em Aparecida do Norte no interior de São Paulo. Os fieis buscam o templo para pagarem promessas, em períodos de romaria e da festa da padroeira, e no decorrer de todo ano realizam visitação para conhecerem a imagem original de Nossa Senhora Aparecida (Oliveira, 2017).

Além do Santuário em São Paulo, existem vários outros pontos para a prática do turismo religioso no Brasil, como: Juazeiro do Norte no Ceará, que possui a maior Romaria de Finados, em 02 de novembro; A celebração do Círio de Nazaré em Belém, que ocorre no segundo domingo de outubro; O Santuário de Nossa Senhora do Bom Socorro e o Santuário de Madre Paulina, em Nova Trento, Santa Catarina, que é a segunda colocada na recepção de turistas anualmente, ficando atrás apenas do Santuário de Nossa Senhora de Aparecida, informações obtidas pelo site ALL (Accor Live Limitless, 2020).

Na Paraíba, de acordo com o Blog Josélio Carneiro, existem diversas propostas de locais para realizar a visitação religiosa como por exemplo o Santuário de Frei Damião em Guarabira; Santuário Padre Ibiapina, em Arara; Santuário de Nossa Senhora de Fátima, em Araruna, o Cristo Redentor, em Itaporanga, além da Cruz da Menina, em Patos.

Por ser um Estado onde as festas juninas fazem parte da tradição, o período junino é onde geralmente há um maior fluxo de visitação, como exemplo na Pedra de Santo Antônio localizada no município de Fagundes. Anualmente recebe uma grande quantidade de turistas durante o mês de junho, especialmente no dia 12 que é comemorado o dia de Santo Antônio, onde na tradição é tido como Santo casamenteiro, e muitas pessoas vão ao local para pagarem promessas ou pedirem para encontrar um parceiro (Ribeiro, 2013).

Essa atividade em regiões com baixo investimento turístico, onde não contam com grandes iniciativas das prefeituras, como por exemplo em cidades de interior, sofrem impactos advindos das ações turísticas que propiciam nas alterações negativas do espaço geográfico.

\subsection{A prática da atividade turística e a degradação do meio ambiente: por uma sustentabilidade do setor}

A atividade turística é amplamente difundida, onde pode-se afirmar que existem poucos lugares inexplorados no mundo e onde não se observe a influência desse fenômeno em maior ou menor intensidade (Beni, 2019). O turismo é uma atividade econômica consumidora dos recursos naturais e gera impactos negativos ao meio ambiente quando não realizado de maneira planejada.

É visto que o aumento da demanda turística tem ocasionado a degradação dos espaços ecológicos. A quantidade de visitantes em meios naturais pode gerar danos irreparáveis aos locais visitados e consequentemente ao meio ambiente. Muitos turistas não têm a noção de como os danos causados pelas suas ações acarretarão grandes impactos ao lugar visitado e a população que ali reside (Cruz \& Almeida, 2017).

Existem lugares turísticos que são fechados à visitação, o que gera prejuízos tanto para a economia, quanto aos visitantes que não podem mais desfrutar de tudo o que aquele local poderia proporcionar em relação as belezas observadas e o lazer. Por isso surge o conceito de turismo sustentável, como uma forma de se evitar as degradações ao meio ambiente natural.

O turismo, para além de ser associado aos indicadores econômicos, está fortemente ligado a fatores ambientais, culturais e sociais. Como o conceito de turismo sustentável deriva da noção de Desenvolvimento Sustentável, ele está associado com as 
preocupações relativas ao meio ambiente e à vida das gerações futuras (Guattari et al., 1990). Quando se trata de turismo sustentável é ressaltado que desenvolvimento da atividade turística não deve ultrapassar os limites do ambiente natural, deve ser economicamente viável e equitativo para as comunidades locais (Körössy, 2008).

Segundo a Organização Mundial do Turismo (OMT, 2003), o turismo sustentável é aquele que atende às necessidades dos turistas de hoje e das regiões receptoras, ao mesmo tempo em que protege e amplia as oportunidades para o futuro. Enquanto que para Swarbrooke (2000), trata-se daquele tipo de turismo que é economicamente viável, mas que não destrói os recursos dos quais a atividade no futuro dependerá, principalmente, o ambiente físico e o tecido social da comunidade local. É necessário a junção da educação ambiental com a prática turística, pois o conhecimento reconstrói sua visão de mundo e passa a se perceber como o único agente capaz de promover a transformação desejada em vários âmbitos, inclusive na questão ambiental (Azevêdo, 2014).

\section{Procedimentos Metodológicos}

Esse trabalho foi desenvolvido com embasamento em pesquisas bibliográficas sobre atividades turísticas religiosas, apresentando os pontos mais frequentados do Brasil. O trabalho trouxe como ênfase a atividade turística religiosa na Pedra de Santo Antônio no município de Fagundes-PB, ressaltando os impactos ambientais quem o local sofre com a ação das atividades turísticas. Além disso, a metodologia foi dividida em duas secções, na primeira parte foi realizado a metodologia de estudo de caso e em seguida a caracterização geográfica do ambiente estudado.

\subsection{Metodologia de estudo de caso}

O estudo de caso possui uma base teórica sólida e segue uma metodologia científica. A partir da coleta de dados empíricos qualitativos, chegam às conclusões do trabalho que, de forma geral, referem-se à análise e à explicação de um acontecimento específico. Essa metodologia pode ser aplicada em casos individuais ou em caso de grupos de indivíduos, grupo de territórios, regiões, cidades. Sendo assim é uma metodologia que se aplica a diversas condições trazendo resultados significantes para a ciência (Meirinhos \& Osório, 2016).

Neste trabalho ela foi aplicada ao ambiente de estudo (Pedra de Santo Antônio), bem como todos que utilizam dessa área para a atividade turística. Buscando avaliar os impactos sociais, econômicos em ambientais, visto que esse método pode ser utilizado para avaliar elementos diversos na área estudo. Essa metodologia ainda proporciona propor medidas mitigadoras que venham a solucionar ou até mesmo amenizar um determinado conflito (Sugai et al., 2007).

\subsection{Caracterização geográfica do local da pesquisa}

Cidade localizada no Planalto da Borborema na Serra do Bodopitá, no agreste paraibano (Figura 1) foi inicialmente povoada pelos Indíos Cariris. A cidade foi inicialmente chamada de Brejo de Canas Bravas e Brejo de Fagundes, até que designou-se a ela o nome Fagundes. O município está incluído na área geográfica de abrangência do semiárido brasileiro, definida pelo Ministério da Integração Nacional em 2005. Esta delimitação tem como critérios o índice pluviométrico, o índice de aridez e o risco de seca, além disso a cidade apresenta em sua grande maioria solos férteis propício ao desenvolvimento de diversas cultivarias (Borges et al., 2020). 
Figura 1. Localização do município de Fagundes-PB.

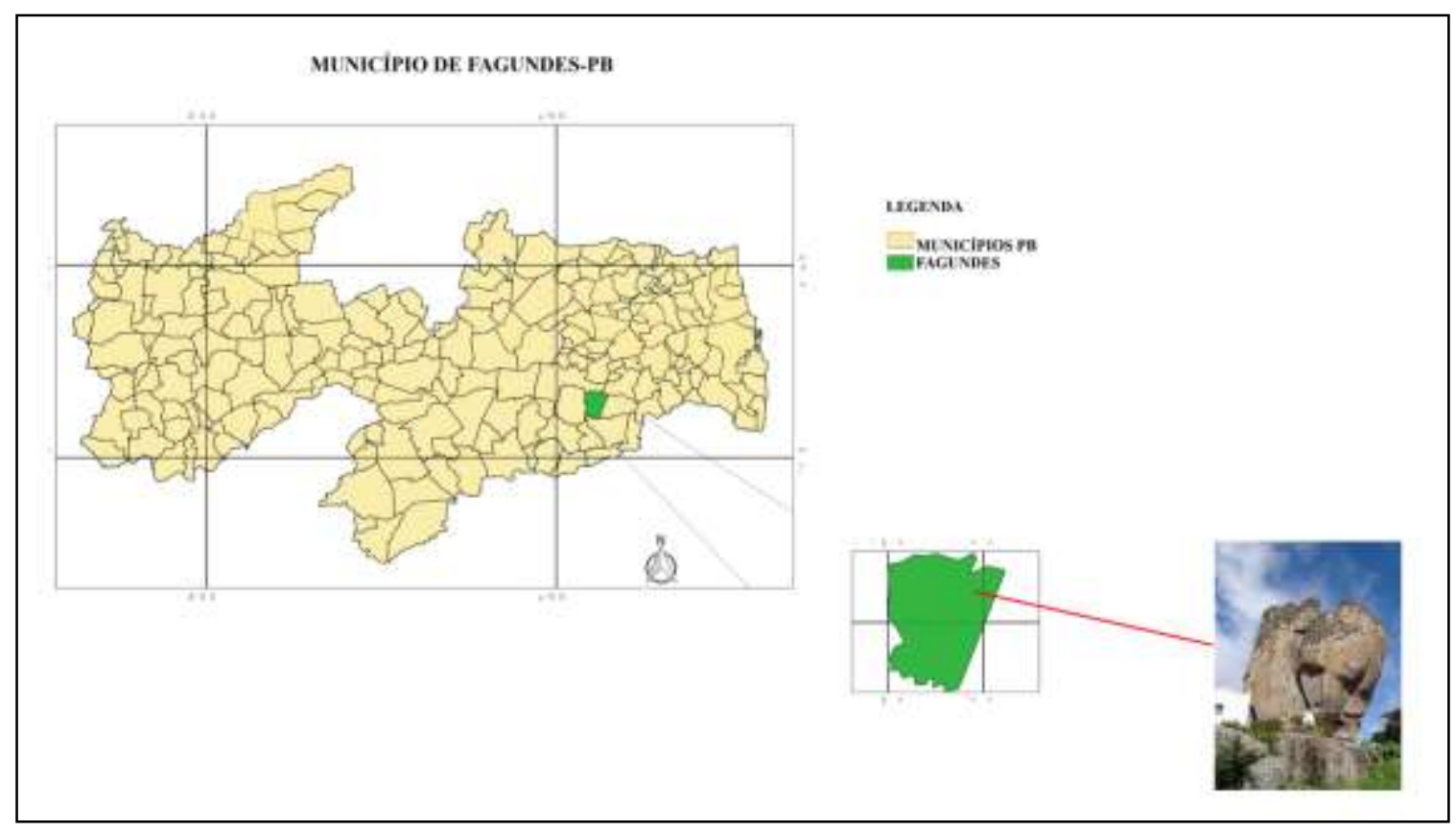

Fonte: Autores (2021).

O município de Fagundes, localiza-se na unidade geoambiental da Depressão Sertaneja, que representa a paisagem típica do semiárido nordestino, caracterizada por uma superfície de pediplanação bastante monótona, seu relevo predominantemente suave-ondulado, cortada por vales estreitos, com vertentes dissecadas. Elevações residuais, cristas e/ou outeiros pontuam a linha do horizonte. Esses relevos isolados testemunham os ciclos intensos de erosão que atingiram grande (Borges et al., 2020).

\section{Resultados e Discussões}

\subsection{O turismo religioso em Fagundes/PB: A Pedra de Santo Antônio}

A Pedra de Santo Antônio, localizada no Município de Fagundes, mais especificamente em sua zona rural, destaca-se não só na Paraíba, mas em toda a região Nordeste, por ser um dos principais pontos turísticos religiosos existentes nessa Região. O renome desse local projeta a cidade a tal ponto que influencia até mesmo na forma em que a mesma é conhecida no Estado, a saber, "cidade da fé". Além disso, esse destaque é devido não apenas a sua beleza geomorfológica, mas, também, por todo misticismo e religiosidade envolta com a história desse lugar, o qual ficou conhecido por realizar pedidos relacionados ao casamento, por intermediação de Santo Antônio. A Figura 2 apresenta a Pedra de Santo Antônio, com destaque para a paisagem ao seu entorno. 
Figura 2. Pedra de Santo Antônio.

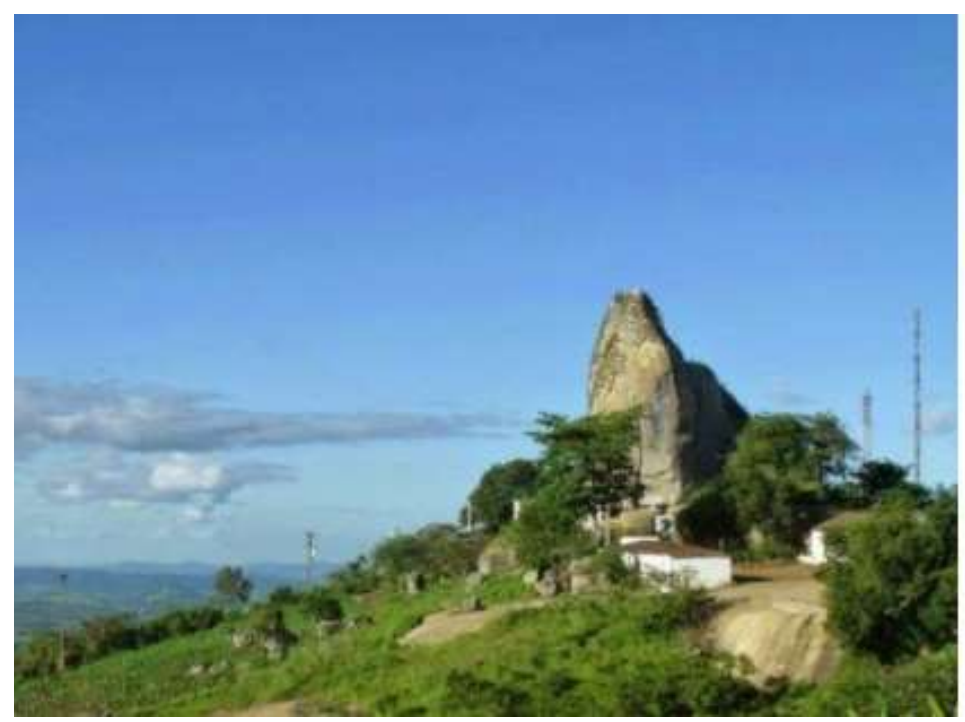

Fonte: Autores (2021)

Segundo o que conta os moradores mais antigos da cidade, uma imagem de Santo Antônio, conhecido popularmente como santo casamenteiro, foi encontrada na pedra entre algumas fissuras e levada para a paróquia da cidade. Esta imagem sempre sumia da Igreja e reaparecia no lugar em que foi inicialmente encontrada, até que na última vez decidiram não retirá-la da pedra. Tal fato logo se tornou público e, dessa forma, começaram a surgir as romarias, sendo a mais antiga a Romaria do Migrante (Figura 3).

Figura 3. Romaria do Migrante.

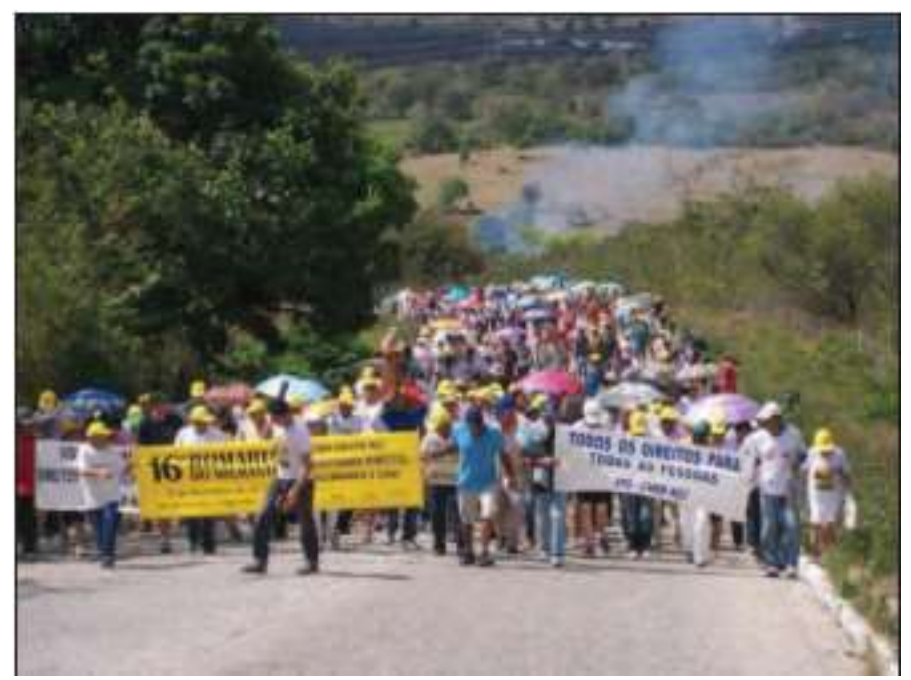

Fonte: Silva, (2012).

De acordo com Silva (2012), romarias anuais passaram a ser realizadas e o local ficou conhecido como "A Pedra de Santo Antônio". Historicamente, o ciclo de visitações religiosas ao lugar foi criado em 1904 permanecendo até hoje, onde anualmente é realizada a Festa da Pedra de Santo Antônio, no dia 13 de junho, dia do calendário católico escolhido para homenagear o Santo. Na Figura 4 é mostrada a Pedra de Santo Antônio localizada no município de Fagundes-PB. 
Figura 4. Pedra de Santo Antônio em Fagundes-PB.

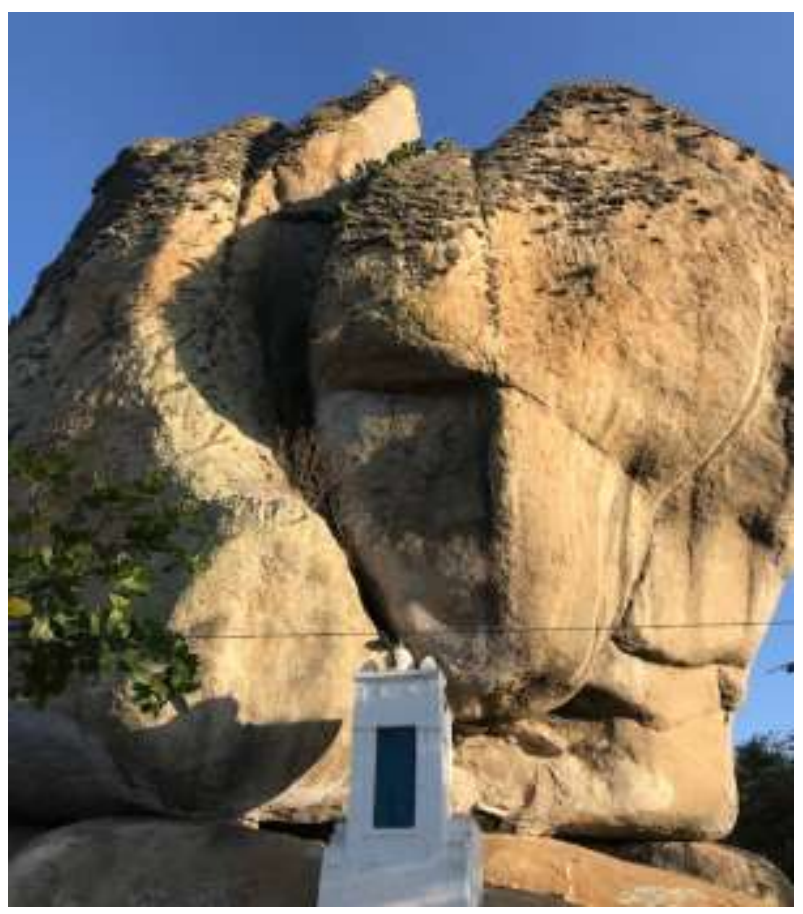

Fonte: Autores (2021).

Segundo a crença popular, o fiel que tiver muita fé em Santo Antônio consegue passar pela fenda até o outro lado da pedra, como um ato de coragem e de penitencia, visando obter como recompensa o sucesso no matrimonio. Solteiros e casados se arriscam nessa travessia como forma de pedir ou agradecer as graças concedidas. Essa tradição é passada para adultos e crianças, assim o local é sempre bem movimentado, principalmente ao pôr do sol, onde a paisagem é deslumbrante e dá para contemplar a cidade de Campina Grande ao longe.

\subsection{A Pedra de Santo Antônio e sua importância para a economia local: um olhar para a atividade turística}

O lugar tem atraído milhares de turistas de diversas localidades todos os anos, o que tem sido favorecido pelo melhoramento da infraestrutura e do acesso ao ponto turístico. Tal fato é, de certa forma, muito importante para a cidade do ponto de vista econômico e cultural. Nesse sentido, Soares e Melo (2010) comenta sobre o desenvolvimento de atividades econômicas das cidades pequenas frisando que:

Uma cidade com recursos naturais valorizados pelo turismo de aventura e ecoturismo ou que possua um conteúdo histórico relevante, com formas arquitetônicas preservadas, até mesmo com elementos culturais e religiosos manifestados através de festejos tradicionais, agregará vantagens indiscutíveis sobre as demais cidades do mesmo porte.

Percebe-se a relevância da Pedra de Santo Antônio enquanto fonte de renda para algumas pessoas, dentre estas destacase os artesãos que fazem e vendem pequenas miniaturas da Pedra para turistas que frequentam. Como exposto na (Figura 5). 
Figura 5. Miniaturas da Pedra de Santo Antônio.

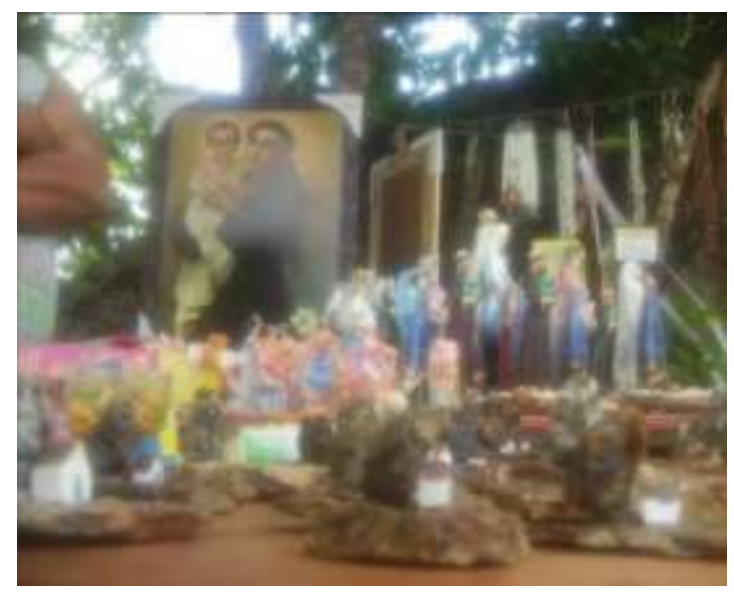

Fonte: Barbosa (2011).

É necessário um maior investimento no setor de comercio, para vendas de artesanatos da cultura local nas proximidades a Pedra de Santo Antônio, como forma de gerar renda e emprego na região.

Conforme Barbosa (2011), o turismo religioso como as demais modalidades turísticas, ocupa espaços e, consequentemente, produz transformações seja de cunho social, espacial, cultural, ambiental entre outros, gera renda e lança cidades consideravelmente pequenas no roteiro turístico, obtendo assim, respaldo de abrangência local e regional.

\subsection{Turismo e meio ambiente: a transformação da paisagem local e a busca pela sustentabilidade}

Quando analisada a atividade turística e o meio ambiente, nota-se no tocante à Pedra de Santo Antônio, a existência de algumas transformações socioambientais, dentre as mais visíveis, destaca-se a alteração da paisagem por meio da quantidade de empreendimentos comerciais instalado ao entorno do local (Figura 6).

Figura 6. Empreendimento em construção.

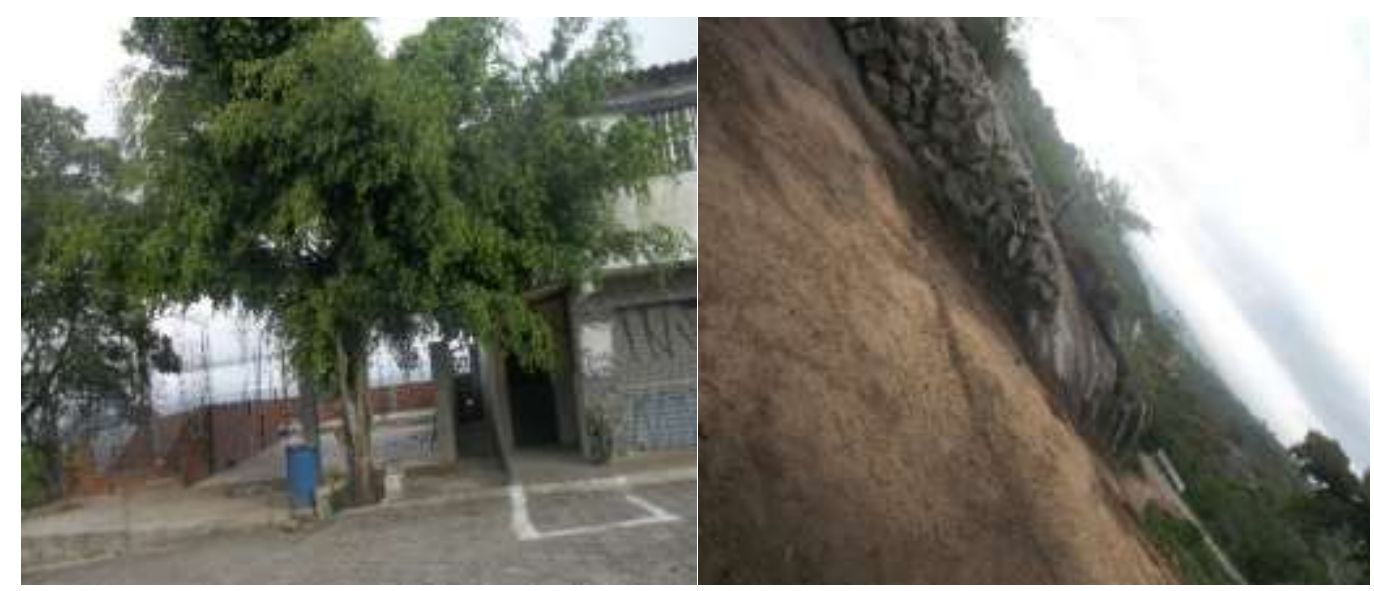

Fonte: Autores (2021).

Outro ponto importante, ainda no que se refere a paisagem, é a modificação na estética da Pedra de Santo Antônio por parte de pichações (poluição visual), bem como na poluição do solo no seu entorno decorrente da pratica turística, deixando evidente os prejuízos ambientais para o local (Figura 7). 
Figura 7. Descarte inadequado de resíduos sólidos.

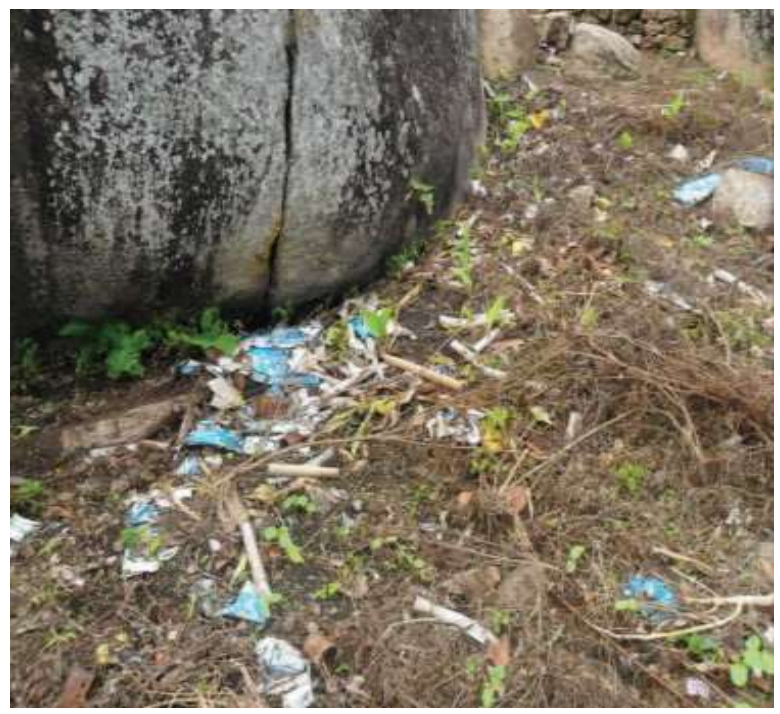

Fonte: Barbosa (2011).

Na Figura 7 é mostrado o descarte inadequado de resíduos sólidos após as festividades e romarias no dia de Santo Antônio. Pela dificuldade no acesso, a prefeitura não realiza limpezas periódicas para a manutenção do local, assim os próprios comerciantes e moradores fazem essa limpeza, só que no geral é de forma não satisfatória para um ponto turístico, que deveria estar sempre limpo para receber os turistas em qualquer época do ano.

O entorno até a chegada a Pedra de Santo Antônio pode seria ser mais explorado em relação ao turismo, buscando empresas que ofertem trilhas, arvorismo, escalada e etc, buscando com que os visitantes voltem a cidade e tenham várias opções como entretenimento.

Desse modo, pode-se perceber potencialidades da Pedra de Santo Antônio como ponto turístico, agregador de religiosos, da natureza e propiciador de renda para algumas pessoas bem com para a própria cidade. Por outro lado, "[...] o turismo em suas atividades é indutor de profundas transformações no espaço geográfico, pois esse constitui o espaço para o turismo" (Castilho, 2008, p.29). Sendo assim, ao mesmo tempo que traz benefícios, nota-se alguns prejuízos tais como a modificação da paisagem do local, assim como no que corresponde a organização espacial.

No geral a Pedra de Santo Antônio é vista como o principal ponto turístico da cidade de Fagundes-PB e com isso movimenta a economia local, sendo fonte de empregos para a população. Algumas melhorias poderiam ser feitas por parte do governo do estado e da prefeitura como: manutenção do local com limpezas periódicas, iluminação adequadas, remoção de entulhos, estacionamento adequado, construção de rampas de acessibilidade para deficientes e ter guias experientes para exposição da história local.

\section{Considerações Finais}

O turismo religioso se constitui em um dos seguimentos mais importantes da Paraíba, no qual tem como palco inúmeras cidades, dentre elas, Fagundes, representada pela Pedra de Santo Antônio. Este local se destaca não só por sua beleza natural, mas também por ter uma íntima relação com o sagrado, algo bastante visto, seja nas histórias locais, seja nas formas religiosas presentes no espaço como a igrejinha localizada ao lado da Pedra.

Tal vínculo entre o indivíduo, a fé e o espaço sagrado resultou em procissões ou romarias que são realizadas todos os anos, fazendo com que esse local seja um dos principais destinos de fies de diferentes localidades do país. Nesse sentido, desde o momento em que a Pedra começou a receber visitantes ela iniciou o processo de transformação espacial em virtude de sua constante exposição. 
Tendo em vista sua importância cultural, religiosa, natural, econômica que traz benefícios para a cidade e os residentes do local onde se situa. Nota-se que ao mesmo tempo em que ela proporciona benefícios como a prática turística, renda para a comunidade, sobrevivência de comerciantes e entre outros, a referida Pedra sofre com impactos ambientais causados por essa interação, como as pichações, resíduos sólidos deixados após festividades e materiais de construção proveniente das residências. Em suma, pode-se inferir que o turismo adapta o ambiente as suas necessidades. Nesse contexto, as modificações estão vinculadas mais aos interesses do capital do que a conservação ambiental do lugar. Por isso é necessário uma melhor fiscalização pelo poder público em relação a transformação da paisagem, de modo que se observe o desenvolvimento socioeconômico e ambiental do setor.

\section{Referências}

ALL Accor Live Limitless, https://all.accor.com/pt-br/brasil/magazine/one-hour-one-day-one-week/turismo-religioso-no-brasil-24380.shtml.

Azevedo, G. C., Cheavegatti-Gianotto, A., Negri, B. F., Hufnagel, B., Silva, L. D. C., Magalhaes, J. V., Garcia, A. A. F., Lana, U. G. P., Sousa, S. M., \& Guimaraes, C. T. (2015). Multiple interval QTL mapping and searching for PSTOL1 homologs associated with root morphology, biomass accumulation and phosphorus content in maize seedlings under low-P. BMC Plant Biol, 15, 172.

Azevêdo, Á. S. C. (2014). A educação ambiental no turismo como ferramenta para a conservação ambiental. Amazônia, Organizações e Sustentabilidade, 3(1), 77-86.

Barbosa, C. M. (2011). A prática do turismo religioso e as transformações socioespaciais na Pedra de Santo Antônio no município de Fagundes- PB. Trabalho de conclusão de curso. UEPB. Campina Grande. 72p. http://dspace.bc.uepb.edu.br/jspui/handle/123456789/5531.

Barreto, M. (2007). Cultura e Turismo: Discussões Contemporâneas. Papirus, Coleção Turismo.

Beni, M. C. (2019). Análise estrutural do turismo. Senac.

Borges, I. M. S., Lima, C. A. O., Fernandes, A. C. G., Nunes, E. A. C., Alves, Á. E. F., Nunes, E. A. C., \& dos Santos Batista, C. (2020). O processo de urbanização e seus impactos ambientais na Cidade de Fagundes, Paraíba: recortes históricos. Research, Society and Development, 9(8), e345985196e345985196.

Blos, A. L. F., \& Ruppenthal, J. E. (2004). O Empreendedorismo no Desenvolvimento Sócio-econômico de Localidades através do Ecoturismo. IV Simpósio Internacional de Qualidade Ambiental.

Castilho, C. J. (2008). Turismo e espaço geográfico: o turismo como uma pratica socioespacial reforçadora de uma economia urbana voltada ao interesse do mercado. In: Viegas, J. M. Turismo e praticas socioespaciais: múltiplas abordagens e interdisciplinaridades. Recife: ed. Universitária da UFPE, p. 15-45.

Correia, C. B. L. (2019). A festa do bode rei na Paraíba: aspectos culinários e sanitários.

Cruz, L. M., \& Almeida, A. A. (2017). O Desenvolvimento Sustentável E O Direito Ambiental: a exploração da atividade turística e a preservação do meio ambiente. CEP, 76, 132 .

Dall'Agnol, S. (2012). Impactos do turismo x comunidade local. SEMINTUR-Anais do VII Seminário de Pesquisa em Turismo do Mercosul. Turismo e Paisagem: relação complexa, 16.

Guattari, F., Bittencourt, M. C. F., \& Rolnik, S. (1990). Las tres ecologías (Vol. 11). Papirus.

Guimarães, M. (2020). Dimensão ambiental na educação (A). Papirus Editora.

Körössy, N. (2008). Do" turismo predatório" ao" turismo sustentável": uma revisão sobre a origem e a consolidação do discurso da sustentabilidade na atividade turística. Caderno Virtual de Turismo, 8(2), 56-68.

Meirinhos, M., \& Osório, A. (2016). O estudo de caso como estratégia de investigação em educação. EduSer-Revista de educação, 2(2).

Nunes, I. M. (2009). Turismo, desenvolvimento e dependência em Cabo Verde (Doctoral dissertation, FEUC). 125p. Universidade de Coimbra. Disponível em: http://hdl.handle.net/10316/11995. Acesso em: 01.Set. 2021.

Oliveira, T. C. D. (2017). Turismo religioso na cidade de Aparecida do Norte: organização e motivação. Trabalho de Conclusão de Curso. 60p. Universidade Federal Fluminense. Disponivel em: https://app.uff.br/riuff/handle/1/5162. Acesso em: 01.Set. 2021.

Organização Mundial Do Turismo (OMT). (2003). Guia de desenvolvimento do turismo sustentável. (trad. Sandra Netz). Bookman.

Ribeiro, F. N. S. (2013). São João passou por aqui? O programa São João da Bahia e ressignificação das festas juninas, um olhar sobre os festejos em Itapitanga. Revista Internacional de Folkcomunicação, 11(23), 128-142.

Rocha, J. P. \& Valle, J. J. L. (2005). El turista que visita la franja costera de la Provincia de Paraíba/Región Nordeste de Brasil. Revista Interface (Porto Nacional), (02). 
Research, Society and Development, v. 10, n. 12, e527101220502, 2021

(CC BY 4.0) | ISSN 2525-3409 | DOI: http://dx.doi.org/10.33448/rsd-v10i12.20502

Ruschmann, D. (2016). Turismo e planejamento sustentável: a proteção do meio ambiente. Papirus editora.

Swarbrooke, J. (2000). Turismo sustentável: conceitos e impacto ambiental, v.1. Aleph.

Silva, V. R. L. M. (2013). É festa: eventos culturais como alternativas para o desenvolvimento turístico local para a cidade de Currais Novos-RN. 14p. Trabalho de Conclusão de Curso. Universidade Federal do Rio Grande do Norte.

Silva, J. W. F. (2012). O espaço geográfico como produto das manifestações socioculturais: o caso do sitio arqueológico Pedra de Santo Antônio município de Fagundes-PB. Trabalho de conclusão de curso. UEPB. Campina Grande. 53p. http://dspace.bc.uepb.edu.br/jspui/bitstream/123 456789/2721/1/PDF\%20-\%20Jos\%C3\%A9\%20Wellington\%20Farias\%20da\%20Silva.pdf.

Soares, B. R., \& Melo, N. A. (2010). Cidades Médias e Pequenas: Reflexões Sobre os Desafios no Estudo dessas Realidades Socioespaciais in: Lopes, D. M. F., Henrique, W. (orgs.). Cidades Médias e Pequenas: Teorias, Conceitos e Estudos de Caso. Salvador: SEI. 250 p. il. (Série estudos e pesquisas, 87) http://www.redbcm.com.br/arquivos/bibliografia/cidades $\% 20 \mathrm{~m} \% \mathrm{C} 3 \%$ A 9 dias $\% 20 \mathrm{e} \% 20$ pequenas $\% 20$ teorias, $\% 20 \mathrm{conceitos} \% 20 \mathrm{e} \% 20 \mathrm{estudos} \% 20 \mathrm{de} \% 20 \mathrm{caso}$.p df

Sugai, M., McIntosh, R. I., \& Novaski, O. (2007). Metodologia de Shigeo Shingo (SMED): análise crítica e estudo de caso. Gestão \& Produção, 14, $323-335$.

Pereira, M. T., Costa, L. C. C., Santos, J. R. A., \& Ribeiro, R. P. R. (2008). Turismo religioso: análise e tendências. V Seminário da Associação Nacional de Pesquisa e Pós-Graduação em Turismo, 2008.

Scótolo, D. \& Netto, A. P. (2015). Contribuições do turismo para o desenvolvimento local. Cultur-Revista de Cultura e Turismo, 9(1), 36-59. 